\title{
Effect of remedial teaching on academic performance of poorly performing students in pharmacology: a Quasi experimental study
}

\section{Sophia B. Modi ${ }^{1 *}$, Bindulatha Nair R. ${ }^{1}$, Libu Gnanaseelan Kanakamma²}

\author{
${ }^{1}$ Department of Pharmacology, ${ }^{2}$ Department of Community Medicine, Government Medical College, \\ Thiruvananthapuram, Kerala, India
}

Received: 27 May 2021

Accepted: 24 June 2021

*Correspondence:

Dr. Sophia B. Modi,

Email: sophiamodi@yahoo.com

Copyright: (C) the author(s), publisher and licensee Medip Academy. This is an open-access article distributed under the terms of the Creative Commons Attribution Non-Commercial License, which permits unrestricted non-commercial use, distribution, and reproduction in any medium, provided the original work is properly cited.

\begin{abstract}
Background: Significant learning difficulties requiring remediation has been observed to be experienced by many medical trainees. Research with regard to individualized remedial teaching based on pedagogical diagnosis is a strong need of the time. The objectives of this study were to assess the effect of remedial teaching in improving academic performance among poorly performing students in pharmacology and to assess factors that could affect academic performance.

Methods: The study was conducted in 2019. Academically poor performing students $(<50 \%$ marks in pharmacology first sessional exam) were selected after getting informed consent. After obtaining baseline information and study skills self-assessment inventory information from all students, academically poor performing students (53 students) were identified and they were randomized into two groups. One group (26 students) received academic support alone. The second group (27 students) received academic support, sessions on study skills, stress-coping strategies and counselling regarding their academic and non-academic problems.

Results: The improvement in test scores among all participants of remedial sessions was statistically significant. Mean pre-test mark was $5.27 \pm 3.6$, post-test was $14.63 \pm 1.24$ and the difference is statistically significant. Though apparently high $10.02 \pm 3.25$ versus $8.59 \pm 3.55$, the post intervention gain in scores is not statistically significant between academic support+special package group versus academic support alone group ( $\mathrm{p}$ value 0.16 ).

Conclusions: Tailored or individualized remediation measures can greatly enhance the academic performance of undergraduate medical students and help them make satisfactory progress on the course.
\end{abstract}

Keywords: Academic performance, Learning difficulties, Medical education, Medical training, Remedial teaching, Remediation

\section{INTRODUCTION}

The academic performance of undergraduate medical students may be subjective to numerous stressors such as academic burden, parental and peer pressure, psychological ailments like depression, burn out, stress, sleep disorders. ${ }^{1,2}$ Furthermore, difficulty in understanding medium of instruction, perceived parental and peer pressure and dissatisfaction with career choice have also been significantly linked with poor performance. ${ }^{3}$

Remediation can be defined as additional teaching above and beyond the standard curriculum, individualized to the learner who without the additional teaching would not achieve the necessary skills for the profession. ${ }^{4}$ Significant learning difficulties requiring remediation in the form of 
an individualized learning plan has been observed to be experienced by $7-28 \%$ of medical trainees. ${ }^{5,6}$

Four steps to effectively approach learning difficulties have been described in the SOAP model. ${ }^{4-7}$ These steps are detecting problems based on a subjective impression; gathering and documenting objective data, according to diagnostic hypotheses; making a pedagogical diagnosis based on this assessment and planning a targeted remediation. The subjective impressions are formed either by direct observation of the learner in action or on formal or informal interactions with the student. But making a pedagogical diagnosis in medical education consists of not only identifying discrepancy between the expected performance standard and the demonstrated performance, and trying to establish the reason for under performance, but also targeted and individualized remediation measures. $^{8}$

It may not be possible to develop standardized remediation processes as the measures have to be individualized according to the need of each student and must be based on pedagogical diagnosis. There is a strong need for further research with regard to evidence based remediation in poorly performing medical students.

\section{Objectives}

The objectives of the study were to assess the effect of remedial teaching in improving academic performance among poorly performing students in pharmacology as assessed by a pre-test and post-test and to assess factors that could affect academic performance.

\section{METHODS}

The type of study conducted was quasi experimental. The study was conducted in the Department of Pharmacology, Government medical college, Kollam. The study subjects were 2nd year MBBS students (currently having pharmacology postings). All students who got less than $50 \%$ marks in the first sessional exam of pharmacology were included. The duration of the study was from July 2019 to August 2019 (2 months).

\section{Sample size}

All students who got less than 50\% marks in the first sessional exam of pharmacology were included.

\section{Sample selection}

Academically poor performing students were selected from the mark list of first sessional exam (all students who got less than $50 \%$ marks). The students were randomized into two groups using random number table. One group received academic support alone. The second group received academic support, sessions on study skills, stresscoping strategies and counselling regarding their academic and non-academic problems.

\section{Inclusion criteria}

Students who got less than $50 \%$ marks and willing to give informed consent were included in the study.

\section{Study tools}

A questionnaire was used to collect the basic sociodemographic information, habits and other factors that can affect academic performance. Study Skills SelfAssessment Inventory was used to assess the study skills of participants and design the remedial sessions. A pre-test and a post-test questionnaire was used to assess effectiveness of educational intervention

\section{Intervention}

The selected students were given remedial teaching (specialized instruction for students deviating from the expected norm).

One group (26 students) received academic support alone. The second group (27 students) received academic support, sessions on study skills, stress-coping strategies and counselling regarding their academic and nonacademic problems.

\section{Data collection process}

After obtaining informed consent, all the second year MBBS students were given a questionnaire enquiring the basic socio demographic information, habits and other factors that can affect academic performance. This was followed by administration of Study Skills SelfAssessment Inventory to assess the study skills of participants and aid in effectively designing the remedial sessions. Then from first sessional exam results in pharmacology, all students who got less than $50 \%$ marks and who were willing to participate in the study was enrolled for remedial teaching. An informal discussion was held with the learners. After taking an informed consent from these students, a pre-test (MCQs and SAQs) on two selected pharmacology topics was conducted one week before the remedial sessions.

The students were randomized into two groups using random number table. One group received academic support alone. The academic support was given after regular class timings and included providing study materials on the two selected pharmacology topics and small group discussions. For the other group, along with academic support, a session on study skills was conducted with emphasis on listening and taking notes in class, time management, study practices, concentration, recall, test anxiety and method of answering questions. In the following week, the second group of students were counselled regarding improvement of academic performance. The students were also introduced to various stress-coping strategies. Post interventional assessment of both the groups was done again by MCQs and SAQs. A 
post-programme questionnaire was administered to the students who participated in the program to assess whether the intervention was of any benefit. The first group was also given study skills and stress management sessions after conclusion of the study.

\section{Statistical analysis}

The data was entered in MS excel and was analysed using the SPSS software. Associations were tested using Chi square test. Mann-Whitney $\mathrm{U}$ test was used to compare scores between intervention and control group and Wilcoxon signed-rank test was used to compare pre and post-intervention performance of the students who participated in the program.

\section{RESULTS}

Seventy eight students participated in the study by completing the study skills self-assessment inventory. Study skills self-assessment inventory was administered to assess the study skills of participants and aid in effectively designing the remedial sessions. Out of 78 students who completed the inventory, $33(42.3 \%)$ were males and 45 $(57.7 \%)$ were females. Only 25 students $(32.1 \%)$ out of 78 participating students had passed first sessional pharmacology examination. It was observed that the pass percentage is more among females and this observation is statistically significant. (Chi-square value $=10.43, \mathrm{df}=1$, $\mathrm{p}=0.001)$.

No association was observed between having a regular hobby and academic performance. Association between smoking (cigarettes) habits and academic performance could not be elicited as all the participants were nonsmokers. No association was observed between academic performance and consumption of caffeine containing beverages or social life outside the college or number of hours spend on extracurricular activities.

Though not statistically significant, better academic performance was observed in participants who slept for optimum hours ( $>6$ hours/day or $<8$ hours/day). It was observed that studying alone or with a colleague or in groups has no statistically significant effect on academic performance. English proficiency also was observed to have no significant effect on exam performance. Majority of the students gave a response of not studying pharmacology on a daily basis.

A total $34.6 \%$ of the students gave the opinion that personal attitude was the most significant factor which improved their learning. Interestingly $71 \%$ of students gave personal attitude and learning patterns as the most important factor adversely affecting their academic performance. $45.5 \%$ of participants gave the opinion that most of the time, they were motivated to participate in the class. ${ }^{6}$
The following results were obtained on application of Study Skills Self- Assessment Inventory on the participants (Table 1).

The different domains under the inventory are studying, memorizing, preparing for test, managing time and taking notes. Each domain has 5 sub-questions under it. For each domain, maximum score is 50 and minimum zero. These scores are divided into two.

A score of 35 to 50 means the skills seems solid. A score 0 to 34 means skills may need a boost.

While looking at participant's domain-wise score, following median scores were obtained. Studying=30, memorizing $=25$, preparing for a test $=30$, managing your time $=15$, taking notes $=27.5$.

According to this inventory, majority of our students fall far below the recommended cut off for skills (Table 1).

The difference observed in skills in the domain studying across passed and failed students in first sessional exams in pharmacology, is statistically significant, $\quad(p=0.012)$ (Mann-Whitney U test).

The difference observed in skills in the domain 'managing your time' across passed and failed students in first sessional exams in pharmacology is statistically significant $(\mathrm{p}=0.005)$ (Mann-Whitney U test).

While analysing the different domains under Study Skills Self-Assessment Inventory using the recommended cut off, for all participants, $42(56.8 \%)$ may need a boost under the domain studying, $47(62.7 \%)$ may need a boost under the domain memorizing, $48(63.2 \%)$ may need a boost under the domain preparing for a test, $67(85.9 \%)$ may need a boost under the domain managing your time, 55 (72.4\%) may need a boost under the domain taking notes.

Though not significant, overall this inventory has identified that all those who failed in the exam may need a higher boost in all the domains when compared to those who passed.

The inventory has identified female participants as 'seems solid' in all the domains when compared to male participants. This difference is statistically significant in the domain memorizing.

\section{Remedial sessions}

Remedial teaching was given to all who failed in pharmacology in first sessional exam (53 students). 29 male and 24 female participants attended the remedial sessions. The participants were divided into two and one group was given academic support alone and the other group was given academic support and specialized instruction. Their baseline characteristics were similar (first sessional pharmacology exam marks, pre-test marks). 
There is no significant difference in distribution of marks in pharmacology first sessional exam in both intervention groups.

The improvement in test scores as assessed by a post-test among participants of remedial sessions was statistically significant (Figure 1). Though there is an observed difference in marks gained between two intervention groups, the difference is not statistically significant ( $\mathrm{t}$ test, $\mathrm{p}$ value 0.16 )

\section{Post program questionnaire}

A post-programme questionnaire was given to the students who participated in the program to assess whether the intervention was of any benefit. $49.1 \%$ of students who attended the remedial teaching sessions strongly agreed that that the sessions helped them to understand the topics better.

The participants agreed that the sessions motivated them to learn, improved their interest in the subject, they would like to use this method for learning more topics, improved their level of confidence, they put effort into learning the material covered in this intervention and they were challenged to do their best work.

The majority of students also believed that they were able to better understand the drugs, easily able to grasp the topic and its contents, study the topics thoroughly, recollect more things and thus improve confidence, could revise again and again and the sessions helped to focus on topics which were most important. The students also commented that this was a very good method to learn pharmacology because of the interactive sessions, creative slides, repetition of important points of the topic and thus very effective in remembering contents of the topic.

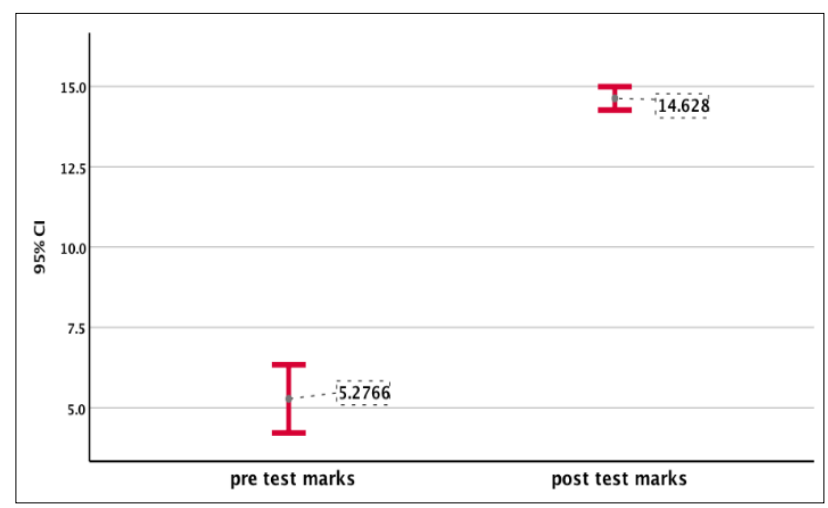

Figure 1: Pre and post-test marks of all participants of remedial session.

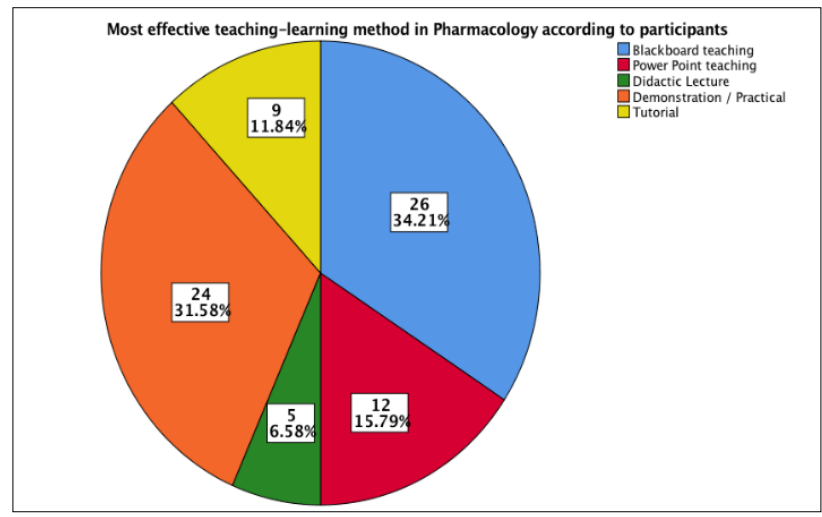

Figure 2: Most effective teaching-learning method in pharmacology according to participants.

Table 1: Domains under study skills inventory versus exam performance.

\begin{tabular}{|c|c|c|c|c|c|}
\hline Domain & Academic performance & $\begin{array}{l}\text { May need a } \\
\text { boost }(\%)\end{array}$ & $\begin{array}{l}\text { Seems solid } \\
(\%)\end{array}$ & Total & P value \\
\hline \multirow{2}{*}{ Studying } & Passed & $10(43.3)$ & $13(56.5)$ & 23 & \multirow{2}{*}{0.122} \\
\hline & Failed & $32(62.7)$ & $19(37.3)$ & 51 & \\
\hline \multirow{2}{*}{ Memorizing } & Passed & $12(48)$ & $13(52)$ & 25 & \multirow{2}{*}{0.063} \\
\hline & Failed & $35(70)$ & $15(30)$ & 50 & \\
\hline Preparing & Passed & $14(56)$ & $11(44)$ & 25 & \multirow{2}{*}{0.365} \\
\hline For a test & Failed & $34(66.7)$ & $17(33.3)$ & 51 & \\
\hline Managing & Passed & $19(76)$ & $6(24)$ & 25 & \multirow{2}{*}{0.085} \\
\hline Your time & Failed & $48(90.6)$ & $5(9.4)$ & 53 & \\
\hline Taking & Passed & $19(76)$ & $6(24)$ & 25 & \multirow{2}{*}{0.62} \\
\hline Notes & Failed & $36(70.6)$ & $15(49.4)$ & 51 & \\
\hline
\end{tabular}

When asked what aspects of the sessions were most beneficial, the most common response was 'interactive sessions', followed by responses such as 'creative slides', 'diagrammatic representations', 'schematic diagrams of mechanism of action and flow charts', 'simplification of topic', 'focus on important points', 'pre-test followed by discussions and post-test', 'repetition of important points', 'presentation of the teacher', 'repeated questions asked by the teacher', and they were also able to discuss doubts and solve them. When asked what they did not like about the sessions, the students did not find any. 
When asked for suggestions to improve teaching in pharmacology, the suggestions received were to include this type of interactive learning with pictures and animations in teaching the subject, so as to give a better understanding of topic (Figure 2).

\section{DISCUSSION}

Literature establishes that the demands of a medical school is difficult to cope with. About 10-15\% of medical students face substantial academic difficulties during their course. ${ }^{12,13}$ Hence, early and timely intervention in the form of targeted remediation is warranted for students experiencing academic difficulties. Even though evidence shows that targeted remediation can benefit such students, little is known about the best approach for remediation in medical students. ${ }^{14}$

This study provided evidence that targeted remediation after assessing the deficiencies in study skills of the students, can substantially improve academic performance of poorly performing medical students. The study emphasized the importance of identification of learning problems at an early stage and intervention in the form of adequate remediation to such students. ${ }^{15}$

A remedial teaching intervention should always be learnercentric, tailored to an individual student's needs. This is because the type of support a student needs can vary, with some students just needing assistance in time management skills or improvement in study techniques whereas other students might need more than one strategy, possibly including enhanced learning support throughout their academic years. ${ }^{15}$

This variability necessitates that every remedial intervention should start with a diagnosis of the individual learner's needs thus enabling teachers to provide individualized remediation to the student. ${ }^{16}$ This attempt at diagnosis is always better done by teachers who are currently teaching the student. The remediation sessions should ideally include multiple, spaced conversations with the student probing into the reasons and attempting an exact identification of remedial measures the student needs. ${ }^{12,13}$ The current study had attempted to achieve the pedagogical diagnosis by two steps. In the first step, we utilized a questionnaire to get a surface knowledge of the sociodemographic background of all the students and his/her study skills, time management skills etc. by a selfassessment questionnaire. ${ }^{17}$ This was followed by further interaction with the study group, attempting to get an indepth knowledge about the reasons for his/ her poor academic performance. Then remedial sessions were designed according to the perceived needs of the students. ${ }^{15}$

Remedial interventions must undergo continuous and rigorous evaluation throughout the academic program. The interventions should be facilitated by teachers capable of pedagogical diagnosis who can also play the role of an encouraging mentor. They should ideally be role models for the students and should possess high degrees of teaching presence and practical wisdom. ${ }^{18}$ This is necessary because significant differences in remediation outcomes have been observed with experienced and inexperienced teachers. ${ }^{18}$ The success of remedial interventions can also be enhanced when conducted in small groups, by experienced teachers who are familiar with the content and process. ${ }^{18}$

\section{Limitations}

The limitations were that the findings of this study may not be generalizable and may be context specific, specific to this cohort or specific for learning pharmacology, small sample size. Even though the Study Skills Self-Assessment Inventory was valid and internally consistent, it is a selfreporting instrument and thus the true approach to learning of students may not be reflected, especially if they answered the questions in a way that they thought would have been the expected answers. Examination of only a small range of demographic variables was also a limitation in the study.

\section{CONCLUSION}

The study proves that remediation measures enabled by simple tools like a study skills inventory can help identify and correct learning difficulties of medical students at an early stage. Such tailored or individualized remediation measures can greatly enhance the academic performance of undergraduate medical students and help them make satisfactory progress on the course.

\section{ACKNOWLEDGEMENTS}

The authors are grateful to all the participants who have participated and provided feedback for completion of the study. The research was supported by MCI nodal centre for faculty development, Government Medical College, Kottayam, Kerala, India.

Funding: No funding sources Conflict of interest: None declared

Ethical approval: The study was approved by the Institutional Ethics Committee, Government Medical College, Kollam

\section{REFERENCES}

1. Mandal A, Ghosh A, Sengupta G, Bera T, Das N, Mukherjee S. Factors affecting the performance of undergraduate medical students: a perspective. Indian J Community Med. 2012;37(2):126-9.

2. Manickam LSS, Rao TSS. Undergraduate medical education: Psychological perspectives from India. Indian J Psychiatry. 2007;49(3):175-8.

3. Givens JL, Tjia J. Depressed medical students' use of mental health services and barriers to use. Acad Med. 2002;77(9):918-21. 
4. Guerrasio J, Garrity MJ, Aagaard EM. Learner deficits and academic outcomes of medical students, residents, fellows, and attending physicians referred to a remediation program, 2006-2012. Acad Med. 2014;89(2):352-8.

5. Yates J, James D. Predicting the "strugglers": a casecontrol study of students at Nottingham university medical school. BMJ. 2006;332(7548):1009-13.

6. Bailey AL. Steinert Y. The "problem" junior: whose problem is it? BMJ. 2008 Jan 19;336(7636):150-3.

7. Boileau E, St-Onge C, Audétat MC. Is there a way for clinical teachers to assist struggling learners? A synthetic review of the literature. Adv Med Educ Pract. 2017;8:89-97.

8. Bearman M, Molloy E, Ajjawi R, Keating J. 'Is there a Plan B?': clinical educators supporting underperforming students in practice settings. Crit Prespect. 2013;18(5):531-44.

9. Sreelekha V, Indla YR, Reddy RR, Rameswarudu M, Swathi A, Yamini D, et al . Study habits and academic performance of first year MBBS students. Int J Med Sci Pub Health. 2016;5(9):1831-4.

10. Sharma P, Singh P, Kalhan S, Garg S. Analysis of factors affecting academic performance of mbbs students in pathology. Ann Int Med Dent Res. 2017;6(6).

11. Berghout E. Factors that influence the academic performance of medical students with prior tertiary education. Sem Schol. 2014.

12. Faustinella F, Orlando PR, Colletti LA, Juneja HS, Perkowski LC. Remediation strategies and students' clinical performance. Med Teach. 2004;26(7):664-5.
13. Yates J. Development of a "toolkit" to identify medical students at risk of failure to thrive on the course: an exploratory retrospective case study. BMC Med Ed. 2011;11(1):95.

14. Shankar N, Ravindranath Y, Ravindranath R, Shah H. Effects of targeted remediation in anatomy for first year medical students. Anat Cell Biol. 2019;52(1):5768.

15. Szumacher E, Catton P, Jones GA, Bradley R, Kwan J, Cherryman F, et al. Helping learners in difficultythe incidence and effectiveness of remedial programmes of the Medical Radiation Sciences programme at university of Toronto and the Michener institute for applied sciences, Toronto, Ontario, Canada. Ann Acad Med Singap. 2007;36(9):725-34.

16. Perin D. Promising Approaches for Remediation. Commun Coll J. 2001;72(1).

17. Winston KA, Vleuten CPVD, Scherpbier AJ. Remediation of at-risk medical students: theory in action. BMC Med Ed. 2013;13(1):132.

18. Audétat MC, Lubarsky S, Blais JG, Charlin B. Clinical reasoning: where do we stand on identifying and remediating difficulties? Creat Ed. 2013;4(6):720-6.

Cite this article as: Modi SB, Nair RB, Kanakamma LG. Effect of remedial teaching on academic performance of poorly performing students in pharmacology: a Quasi experimental study. Int J Basic Clin Pharmacol 2021;10:961-6. 